\title{
Socio demography of mental retardation: A community-based study from a goitre zone in rural sub-Himalayan India
}

\author{
Shailja Sharma, Sunil Kumar Raina, Ashok Kumar Bhardwaj, Sanjeev Chaudhary', Vipasha Kashyap, Vishav Chander \\ Departments of Community Medicine and ${ }^{1}$ Paediatrics, Dr. Rajendra Prasad Government Medical College, Himachal Pradesh, India
}

\section{ABSTRACT}

Introduction: Mental retardation is one of the most common disabilities of childhood which can be prevented by timely identification of the causative agent and an adequate management accordingly. District Kangra lies in the sub-Himalayan belt and forms a part of the $2400 \mathrm{~km}$ long goitre belt along the southern slopes of the Himalayas. Objective: To study the prevalence of mental retardation among children (1-10) years of age. Materials and Methods: A two-phase cross-sectional study was conducted in the rural area of district Kangra. A 30-cluster sampling technique was used to screen a population of children 1-10 years of age from five randomly selected panchayats (village government units) of district Kangra. The screening was based on a modified version of the ten questions screen, adapted to the local population. In the first phase a door to door survey was done to identify suspects of mental retardation. In the second phase, the children found positive in the first phase were called for examination by the pediatrician to confirm mental retardation. Results: A total of 2420 children were screened in the first phase of which 95 tested positive. About 52 of these children were found to be mentally retarded in the second phase giving a prevalence of $2.15 \%$. The $69 \%$ of these children belonged to the lower middle class and $28.3 \%$ belonged to middle class families using the Uday Parekh scale for assessment of the socio-economic status. Conclusion: Prevalence of mental retardation is high in district Kangra of Himachal Pradesh in comparison to other states of India. This could be attributed to the good primary health care in Himachal Pradesh where institutional deliveries are about $70 \%$. This may have led to better survival of children with congenital disorders and those that suffer perinatal trauma.

Key words: Goitre, mental retardation, rural, socio-demography

\section{Introduction}

Mental retardation is defined by the American Association on Mental Retardation (AAMR) as "significantly sub-average intellectual functioning existing concurrently with related limitations in two or more of the following applicable adaptive skill areas: Communication, self-care, home living, social skills, community use, self-direction, health and safety, functional academics, leisure and work, with such limitations manifested "before the age of $18 .{ }^{\text {"[1] }}$

\begin{tabular}{|l|l|}
\hline \multicolumn{2}{|c|}{ Access this article online } \\
\hline Quick Response Code: & Website: \\
\hline & www.ruralneuropractice.com \\
\cline { 2 - 2 } & \\
\hline
\end{tabular}

Mental Retardation is one of the most common disabilities occurring in childhood. ${ }^{[2]}$ Studies of the frequency of and risk factors for cognitive disorders in children have almost entirely been limited to the developed countries where service records and registries provide feasible means of case identification. ${ }^{[3]}$ Pilot studies of severe mental retardation in selected populations conducted in India and Pakistan have reported extraordinarily high prevalence estimates in the range of $12-24 / 1000 .{ }^{[4]}$ Because some of the specific causes and risk factors that are now uncommon in developed countries remain highly prevalent in less developed countries, and because child survival is beginning to improve in some countries (a situation which in developed countries appears to have resulted in increase in the prevalence of childhood disabilities), the possibility of an elevated frequency of severe mental retardation in less developed countries is plausible and requires confirmation.

\section{Address for correspondence:}

Dr. Sunil Kumar Raina, Department of Community Medicine, Dr. Rajendra Prasad Government Medical College, Kangra, Tanda, Himachal Pradesh, India. E-mail: ojasrainasunil@yahoo.co.in 
District Kangra forms a part of the $2400 \mathrm{~km}$ long goitre belt along the southern slopes of the Himalayas. Various studies have been carried out in this district on iodine deficiency and prevalence of goitre, but even after an extensive search on PubMed, no work on the prevalence and causes of mental retardation carried out in this district were found. Iodine deficiency forms one of the major causes of mental retardation among children. Prevalence estimates of mental retardation are important for determining the educational and health care needs of the children with this condition. Population-based epidemiological studies on childhood disabilities are needed for identifying risk factors and causes, and for needs assessment to facilitate planning of services for children and families with special needs. Studies across populations need to be undertaken as a consideration of culture is essential in the process of the interview, case formulation, diagnosis, and treatment of culturally diverse individuals. Furthermore, the evaluation of these individuals raises many issues that clinicians need to address to formulate an accurate diagnosis and treatment plan that will be acceptable to the patient.

\section{Materials and Methods}

Kangra district of Himachal Pradesh lies between $31^{\circ} 21^{\prime}$ to $32^{\circ} 59^{\prime} \mathrm{N}$ latitude and $75^{\circ} 47^{\prime}$ to $77^{\circ} 45^{\prime} \mathrm{E}$ longitude. It is situated on the southern escarpment of the Himalayas. The total geographic area of Kangra district is 5,739 sqkm.

A cross-sectional two-phase study was carried out in a single block in the rural area of district Kangra, with a population of about one lakh block. A total of five panchayats with a population of about 12,000 were randomly selected. During the first phase of the study, a door to door survey was conducted. The consent for the participation in the study was obtained from the guardian (preferably parents) of the children. All the children within the age group of 1-10 years were screened using the ten questions screen. ${ }^{[5]}$ The ten questions screen has been used by the researchers across populations for the assessment of mental retardation. ${ }^{[3-5]}$

The sensitivity of ten questions as a global screen for serious cognitive, motor and seizure disabilities is high (84-100\%). Five of the questions focus specifically on cognitive development, two questions relate to movement disability, and one question each focuses on seizures, vision and hearing respectively. ${ }^{[5]}$ Importantly the children of this age group represent iodine nutriture of a community. ${ }^{[6]}$

\section{Questionnaire development}

An expert group comprising of one bilingual investigator (post-graduate student), two public health specialists, and one pediatrician from Himachal Pradesh developed a series of measures for the local population that included the same general cognitive domains, as similar as possible to English version of ten questions screen in a language suited for the local population.

The expert group sat together and worked on the possible alternatives to the English version of ten questions screen (TSQ). An effort was made to arrive at consensus in development of questionnaire and a question was accepted for the inclusion, if accepted upon by all the expert group members.

\section{Pre-pilot}

The pre-pilot centered on information-gathering for the suitability of the questionnaire developed. For this purpose, we sat down with 25 subjects (parents of children 1-10 years of age) and went through the questions together to identify potential problems in the applicability of the local version of TSQ. After a pre-piloting session, we amended the questionnaire before piloting with another group of 25 testers. The amended version was again based on unanimous decision by the expert group.

This process was aimed at arriving at a scale wherein questions were unambiguous, appropriate and acceptable to respondents. We also tested the layout at this stage.

\section{Pilot phase}

After the appropriate modifications were made to the test items, an age-stratified (1-3, 4-6, and 7-10) random sample of 50 subjects (parents of children 1-10 years of age) was drawn from the Shahpur census database for a pilot study. The subjects were selected by simple random technique. After starting from the central part of Shahpur (bus stand area), one of the lanes was selected randomly by the lottery method using a currency note. Subjects were approached in their homes starting from the left side of the lane (after the toss of a coin in choosing the sides of lane). The process was repeated in similar manner in other lanes till a desired sample size of 50 was achieved.

Using a global interpretation of the ten questions, a child was considered positive for any disability if a response to any one question indicated potential disability. Those testing positive in the first phase were clinically examined by a pediatrician in the Department of Pediatrics. 


\section{Clinical evaluation}

Clinical evaluation was performed (without the knowledge of the screening result) by a pediatrician. The diagnosis of mental retardation was made after psychological assessment based on nonverbal scales from 1985 revision of the Stanford-Binet intelligence test. The assessment of mental retardation was also based on the child's developmental history and a structured observation of the child's functioning in language, response to instructions and his or her ability in motor skills and behavior. A classification of a child as mentally retarded implied significantly sub-average intellectual functioning existing concurrently with related limitations in two or more of the following applicable adaptive skill areas:

- Communication

- Self-care

- Home living

- Social skills

- Community use

- Self-direction

- Health and safety

- Functional academics

- Leisure and work.

A total of 2420 children were screened in the first phase of which 95 tested positive. These 95 children were examined in the Department of Pediatrics at Dr RPGMC Tanda. About 52 of these children were found to be mentally retarded.

Socio-economic status was defined on the basis of modified Uday Parekh scale. The scale has been used by authors for assessment of socio-economic status among rural populations in India. The variables included in this scale are as under:

- Caste (1-6)

- Occupation (0-6)

- Education (0-6)

- Land (0-6)

- Social participation (0-6)

- Family members (1-2)

- House (1-6)

- Farm power (1-6)

- Material possession $(\max =6)$.

Parental permission was sought before including the child up to 7 years of age in the study after ensuring the following things:

- The process was conducted in a manner and location that ensures participant's privacy,

- giving adequate information about the study in a language understandable to the participant,
- providing adequate opportunity for the participant to consider all options,

- responding to the participant's questions,

- ensuring the participant has understood the information provided,

- obtaining the participant's voluntary agreement to participate, and

- continuing to provide information as the participant or research requires.

In children above 7 years of age, an assent from children in addition to parental permission after fulfilling the above criteria was obtained.

\section{Results}

The crude prevalence of mental retardation in this region was found to be $2.15 \%$, which is higher than prevalence reported in other parts of the country. According to the modified Uday Parekh scale used for assessing the socio-economic status of the families of the children examined in the first phase, $686(28.3 \%)$ belonged to middle class, $1670(69 \%)$ belonged to the lower middle class and $64(2.6 \%)$ belonged to the lower class [Table 1 ].

Maximum children with mental retardation belonged to the lower middle class, wherein of the 1670 children examined, 41 were found to be mentally retarded (2.4\%). A total of 8 children of the 686 belonging to the middle class were found to be mentally retarded $(1.16 \%)$ and 3 children of the 63 , belonging to the lower class, were found to be mentally retarded (4.7\%) [Table 2].

The prevalence was more among males as compared to the female children. About $59.6 \%$ (31/52) of the mentally retarded children were males. Of these $16.1 \%(5 / 31)$ male children belonged to the middle class, $77 \%(24 / 31)$

Table 1: Socio-economic status (using Uday Parekh scale) of the study population

\begin{tabular}{lccc}
\hline SES & Male & Female & Total \\
\hline GRADE 3 middle class (24-32) & 349 & 337 & $686(28.3)$ \\
GRADE 4 lower middle class (13-23) & 867 & 803 & $1670(69)$ \\
GRADE 5 lower class (below 13) & 35 & 28 & $64(2.6)$ \\
\hline
\end{tabular}

Values in parenthesis are percentages

Table 2: Socio-economic status (using Uday Parekh scale) of the mentally retarded

\begin{tabular}{lcc}
\hline SES & Population & Mentally retarded children \\
\hline GRADE-3 & 686 & $8(1.16)$ \\
GRADE-4 & 1670 & $41(2.4)$ \\
GRADE-5 & 64 & $3(4.7)$ \\
\hline
\end{tabular}

Values in parenthesis are percentages 
belonged to the lower middle class and $6.45 \%(3 / 31)$ belonged to the lower class. About $40.3 \%$ (21/52) of mentally retarded children were females. Of these $14.2 \%$ (3/21) belonged to the middle class, $80.95 \%(17 / 21)$ lower middle class and $4.7 \%(1 / 21)$ belonged to the lower class.

The variable which is of interest, as it was found to be statistically significant from among the Uday Parekh scale was the education status of the father $(P=0.001)$ [Table 3]. About $46.1 \%$ children were from families where the father had attended high school and $28.8 \%$ of the mentally retarded belonged to fathers who had attended middle school.

\section{Discussion}

The prevalence of mental retardation has greatly varied across the different countries of the world with Atlanta, Georgia, US $0.33 \%,{ }^{[7]}$ UK $0.34 \%,{ }^{[8]}$ Australia showing a prevalence of $0.3 \%,{ }^{[9]}$ Canada with a prevalence of $0.72 \%{ }^{[10]}$ and China showing a prevalence of $0.93 \% .^{[11]}$ In a study conducted in eight developing countries, a variation in prevalence of mental retardation was found from $0.9 \%$ (Philippines) to $15.6 \%$ in Bangladesh. ${ }^{[12]}$

The prevalence of mental retardation in India has shown a variation from $0.72 \%$ in $\mathrm{J}$ and $\mathrm{K},{ }^{[3]} 0.3 \%$ in Mangalore ${ }^{[13]}$ to $2.3 \%$ in Karnataka. ${ }^{[14]}$ Our study revealed a prevalence of $2.15 \%$, which is on the higher side as compared to the rest of the country. The survival rate of children in Himachal Pradesh is quite high due to the efficient primary health care system in the state. The percentage of institutional deliveries in Himachal Pradesh is high (70\% in 2011-12). This probably leads to the survival of children who have congenital anomalies or suffer birth trauma and later present with mental retardation. The study reveals that most of the children belonged to the lower middle class and lower class families. The living conditions of the family, the occupation and the education of the father could be an important factor in the development or the diagnosis of mental retardation. Most of the fathers had attended high school. This could possibly be because educated parents are able to identify mental disorders and delay in developmental milestones better than lesser educated parents and hence are able to give better history. The fear of social stigma may also be lesser among the educated people than the uneducated ones.

The low-socio-economic status is the strongest and the most consistent predictor of mild mental retardation. Islam et al. in their study in Bangladesh found the
Table 3: Education status of fathers of mentally retarded children ( $N=52$ )

\begin{tabular}{lc}
\hline Education status & Number of mentally retarded children \\
\hline High school & $24(46.1)$ \\
Middle school & $15(28.8)$ \\
Primary & $3(5.8)$ \\
Can read or write & $2(3.8)$ \\
Illiterate & $7(13.5)$ \\
\hline Values in parenthesis are percentages. $\chi^{2}: 48.576$, df:21, $P=0.001$ (significant)
\end{tabular}

prevalence of severe mental retardation to be $0.5 \%$ and mild-mental retardation $0.14 \%$. Prevalence of mild-mental retardation was found to be strongly and significantly associated with low-socio-economic status. ${ }^{[15]}$ Strome et al. in a cross-sectional study in Oslo, Norway found a high risk of mild mental retardation in families with a low-socioeconomic status. However, they also state that parents of children with severe mental retardation belonged to the higher socio-economic strata ${ }^{[16]}$ A study in Australia showed that children of mothers in the most disadvantaged $10 \%$ had five times more the risk of mild and moderate ID as compared with those in the least disadvantaged $10 \% .{ }^{[17]}$

This highlights the role of poverty and social deprivation in the development of mental retardation. Perinatal infections, post-natal infections and lack of screening for congenital/chromosomal disorders are some of the common causes of mental retardation which are more often seen in the lower income strata of society. Further, the prevalence of certain other childhood conditions like cerebral palsy or other motor deficits, language delays, or hearing needs to worked out for arriving at true prevalence of mental retardation. Such motor or sensory impairments can mimic cognitive impairment, but are not in themselves causes of it. As children mature, some develop anxiety or depression if they are socially rejected by other children or if they are disturbed by the realization that others see them as different and deficient. Well-managed, inclusive school programs can help to maximize social integration, thereby minimizing such emotional responses. Appropriate medical care and education given to the lower middle class families could go a long way in reducing mental retardation among children.

\section{References}

1. Kiely M. The prevalence of mental retardation. Epidemiol Rev 1987;9:194-218.

2. Chen J, Simeonsson RJ. Prevention of childhood disability in the People's Republic of China. Child care Health Dev 1993;19:71-88.

3. Raina SK, Razdan S, Nanda R. Prevalence of mental retardation among children in RS Pura town of Jammu and Kashmir. Ann Indian Acad Neurol 2012;15:23-6. 
4. Durkin MS, Hasan ZM, Hasan KZ. Prevalence and correlates of mental retardation among children in Karachi, Pakistan. HYPERLINK "http:// www.ncbi.nlm.nih.gov/pubmed/?term $=$ Prevalence + and + correlates + of + mental + retardation+ among + children + in + Karachi $\% 2 C+$ Pakistan" $\backslash$ “ "American journal of epidemiology." Am J Epidemiol 1998;147:281-8.

5. Durkin MS, Hasan ZM, Hasan KZ. The ten questions screen for childhood disabilities: It's uses and limitations in Pakistan. HYPERLINK "http://www.ncbi.nlm.nih.gov/pubmed/?term=The+Ten+Questi on + Screen+for + childhood + disabilities $\% 3$ Aits + uses+in+Pakistan."

$\backslash \mathrm{o}$ "Journal of epidemiology and community health." J Epidemiol Community Health 1995;49:431-6.

6. WHO/UNICEF/ICCIDD. Indicators for assessing iodine deficiency disorders and their control through salt iodization. Geneva: WHO/NUT/94.6;1994.

7. Bhaskin TK, Brocksen S, Avchen RN, Van Naarden Braun K. Prevalence of four developmental disabilities among children aged 8 years--Metropolitan Atlanta Developmental Disabilities Surveillance Programmes, 1996 and 2000. MMWR Surveill Summ 2006;55;1-9.

8. Peckham C, Pearson R. The prevalence and nature of ascertained handicap in the National Child Development Study (1958 cohort). Public Health 1976;90:111-21.

9. Leonard H, Petterson B, Bower C, Sanders R. Prevalence of intellectual disability in Western Australia. Paediatr Perinat Epidemiol 2003;17:58-67.

10. Bradley EA, Thompson A, Bryson SE. Mental retardation in teenagers: Prevalence data from the Niagara region, Ontario. Can J Psychiatry 2002;47:652-9.

11. Xie ZH, Bo SY, Zhang XT, Liu M, Zhang ZX, Yang XL, et al. Sampling survey on intellectual disability in 0 approximately 6-year-old children in China. J Intellect Disabil Res 2008;52:1029-38.
12. Stein Z, Belmont L, Durkin M. Mild mental retardation and severe mental retardation compared: Experiences in eight less developed countries. Ups J Med Sci Suppl 1987;44:89-96.

13. Bhagya B, Ramakrishna A. Prevalence of mental retardation among chidren in Mangalore. Nitte Univ J Health Sci 2013;3:63-6.

14. Kumar SG, Das A, Bhandary PV, Soans SJ, Harsha Kumar HN, Kotian MS. Prevalence and pattern of mental disability using Indian disability evaluation assessment scale in a rural community of Karnataka. Indian J Psychiatry 2008;50:21-3.

15. Islam S, Durkin MS, Zaman SS. Socioeconomic status and the prevalence of mental retardation in Bangladesh. Ment Retard 1993;31:412-7.

16. Strømme P, Magnus P. Correlations between socioeconomic status, IQ and aetiology in mental retardation: A population-based study of Norwegian children. HYPERLINK "http://www.ncbi.nlm.nih.gov/ pubmed/10741531" \o "Social psychiatry and psychiatric epidemiology." Soc Psychiatry Psychiatr Epidemiol 2000;35:12-8.

17. Leonard H, Petterson B, De Klerk N, Zubrick SR, Glasson E, Sanders R, et al. Association of sociodemographic characteristics of children with intellectual disability in Western Australia. Soc Sci Med 2005;60:1499-513.

How to cite this article: Sharma S, Raina SK, Bhardwaj AK, ChaudharyS, Kashyap V, Chander V. Socio demography of mental retardation: A community-based study from a goitre zone in rural sub-Himalayan India. J Neurosci Rural Pract 2015;6:165-9.

Source of Support: The study has been funded by a grant from Indian Council of Medical Research (ICMR) Conflict of Interest: None declared. 